eighteen months after operation. The animal was in good condition.

There were slight peritoneal adhesions between the intestines and the anterior wall of the abdominal cavity at one point along the line of incision. The right ovary appeared normal and was much larger than at the time of transplantation (Fig. 1). It was whitish pink and showed a few dark spots. The left ovary was represented by a cystlike mass the size of a navy bean. It was dark in color and soft to the touch. When the capsule, which was markedly thickened, was opened, a small gelatinous mass was found. It was clear to pale yellow, and measured about 10 by 4 by $2 \mathrm{~mm}$.

The lumen of the upper end of the right fallopian tube appeared to be somewhat narrowed. Communication between the fimbriated extremity and the ovary was unobstructed (Fig. 2). The lumen of the left fallopian tube was patent.

Histologic examination of the right ovary revealed abundant normal histologic elements (Fig. 3), including corpora luteum (Fig. 4). The left ovary had undergone complete colloidal degeneration, at least so far as the reproductive elements were concerned.

As no attempt at mating the animal

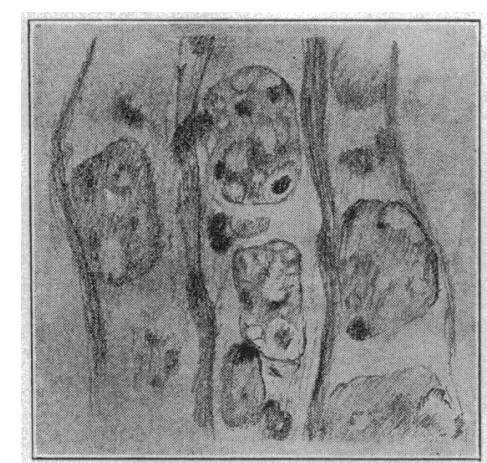

Fig. 4.-Camera lucida drawing of a few cells of a corpus liteum in the right engrafted ovary. was made, the experiment is not conclusive as to the possibility of pregnancy.

The result leads us to believe that ovarian transplantation in dogs is not only feasible but also offers a promising means of obtaining information regarding optimum conditions for success as well as heredity.

\section{SYPHILIS OF THE STOMACH}

\section{A REPORT OF EIGHT CASES WITH ROENTGENOLOGIC FINDINGS *}

WILLIAM A. DOWNES, M.D. AND

LEON T. LE WALD, M.D. NEW YORK

It is generally stated in textbooks on diseases of the stomach that syphilis of this organ is of rare occurrence, and that it is found in scarcely more than 1 per cent. of patients afflicted with the disease. The advent of routine blood examinations, however, and the great advance made in the diagnosis of all gastro-intestinal lesions by the use of the Roentgen ray prove that this contention can no longer be held.

Since June 1, 1913, eight cases of syphilis of the stomach, in which the diagnosis was established with a fair degree of certainty, have been admitted to the ward service of St. Luke's Hospital. Five of these patients suffered from the symptoms of obstruction, and according to the assignment of cases by region, in effect since that date, were referred to one of us (W. A. D.) for operation. The other three were

* From the Surgical Service and Roentgen-Ray Laboratory, St. Luke's Hospital.

* Read before the New York Surgical Society, March 24, 1915.

* Because of lack of space, this article is abbreviated in THE Journal by omission of some of the case reports and illustrations. The complete article appears in the authors' reprints. A copy of the latter will be sent by the authors on request. cared for in the medical service, as no indication for surgical intervention existed at the time.

Syphilis appears in the stomach as a late manifestation of the disease in both the congenital and the acquired types. Jerome Meyers ${ }^{1}$ states that the age in the youngest recorded case of the acquired form is 18 and the oldest 60 . In the congenital cases, gummas have frequently been found at necropsy in the stomach of the new-born.

The ages in our cases were 14 and 17 in the congenital type and $22,23,34,42,62$ and 63 in the acquired.

Diffuse syphilitic gastritis has been described, and histologic examination in such cases has shown the changes of generalized gummatous infiltration of the submucosa. In the great majority of instances, however, the disease appears in the form of localized gummas, either single or multiple. The lesions may be situated in any part of the stomach, but seem to occur most frequently in the pars pylorica, involving either the lesser or greater curvatures, or both. The gummatous deposits are described by pathologists as starting in the submucosa and spreading gradually to the other coats. These deposits pass through the stages of infiltration, ulceration and cicatrization, in varying degrees. One portion of the wall may remain infiltrated while another passes on to ulceration or may become cicatricial. Definite pyloric stenosis may occur either as a result of the gummatous infiltration, cicatrization of the ulcer or perigastric adhesions. Obstruction from the combination of these conditions necessitated operation in five of our cases. Besides the lesions in the stomach wall, other syphilitic manifestations are usually present, such as marked perigastric adhesions, changes in the liver capsule and gummas of the liver, and extensive involvement of the gastrohepatic and gastrocolic lymph glands, as well as other constitutional and local evidences of the disease.

The symptoms of gastric lues when considered in a general way differ very little from those of other lesions of the stomach of equal extent and like location; but when carefully analyzed, several striking differences become apparent. To begin with, the pain lacks the periodicity of the average simple ulcer-it is not so much influenced by the taking of food and is frequently referred to as gnawing in character; it is, however, persistent, and was an important symptom in the cases observed by us. Vomiting was a marked symptom in our cases almost from the beginning. This is probably accounted for early, by the gummatous infiltration, and later on, by the cicatrization and adhesions, possibly too, indirectly from the disturbed liver function. Although small quantities of blood have been found in the gastric analyses of the cases, and a few claim to have had tarry stools, hemorrhage has not been so frequent or severe as in simple ulcer; this is especially striking when the long history of many of the cases is taken into consideration. Our observation in this respect corresponds with the experience of Fenwick, ${ }^{2}$ who states

1. Meyers, Jerome: Albany Med. Ann., October, 1912.

1. Fenwick, and Soncer and Other Tumors of the Stomach, Philadelphia, P. Blakiston, Son \& Co., 1902, p. 313. 
that the infrequency of hematemesis in these cases helps to differentiate them from simple ulcers. On the other hand, Lockwood ${ }^{3}$ reports a fatal case from hemorrhage. The predominating feature of the disease clinically is the extreme loss in weight, which in one of the cases here reported amounted in eighteen months to one half of the patient's former weight.

Gastric analysis was omitted in Case 5 , on account of constant vomiting and disinclination on the part of the patient. In Case 6 , there is no record that an analysis was made. In Cases 1,7 and 8 , the examination showed absence of free hydrochloric acid and a combined acidity of 32,16 and 14 , respectively. In these cases there was extensive involvement of the stomach wall as shown by the roentgenograms and in Case 1 by operation. In Cases 2 and 3 , in which the symptoms were those of pyloric stenosis and the lesions were demonstrated at operation to be at the pylorus, free hydrochloric acid was 30 and 36 , with a combined acidity of 52 and 70; while in Case 4, in which there was hour-glass contraction with constriction at the pylorus, the analysis showed free hydrochloric acid 13 , total acidity 34. Lactic acid was absent in every case. The guaiac test for blood was positive in five cases. While these findings are in no wise conclusive, they would seem to suggest that there is absence of free hydrochloric acid, and a low total acidity in the cases, with extensive involvement of the gastric mucosa unaccompanied by special involvement of the pylorus, and that the distinctive pyloric stenosis type without diffuse infiltration of the mucosa shows the usual findings of ulcer in that region.

The diagnosis of gastric syphilis can be established

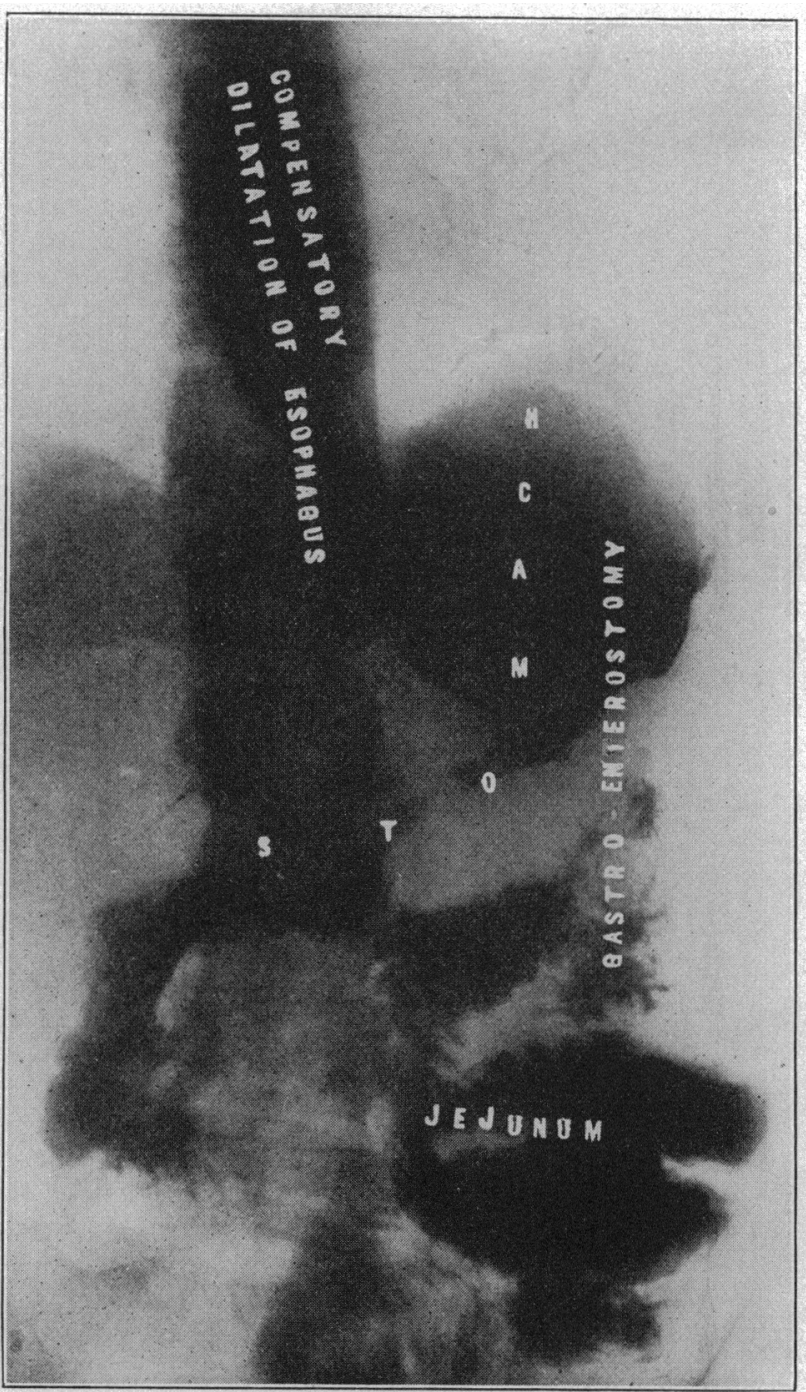

Fig. 1 (Case 1).-Girl, aged 14. Note dumb-bell-like appearance due to sclerosis of body of stomach. After gastro-enterostomy, most of food going through opening, but enough passing through stenosed portion to outline it. Note compensatory dilatation of esophagus. ods of treatment, and it is unlike malignancy in that there is not the steady and continuous progress to a fatal termination. With such a history and due consideration given to the symptoms previously enumerated, the added evidence of a positive Wassermann reaction and the roentenographic findings of deformity of the stomach make the diagnosis practically certain. Finally, the value of the therapeutic test must be given due weight. That mixed treatment and salvarsan will produce temporary improvement in old ulcers or even certain cancer cases there is no doubt, but the benefit is of short duration, where, as in the class of cases under consideration, there is a return to normal health; and if the lesion in the stomach has not reached the cicatricial stage, this organ may be restored to its former condition.

Two of our cases were of the congenital type, two gave definite histories of chancre and in one the husband gave a positive Wassermann. The history as to primary infection in the remaining three was negative. The Wassermann reaction was four plus positive in every case. Roentgenograms $s$ how ed definite changes in the shape and size of the stomach in six cases, and in the other two demonstrated a marked degree of pyloric stenosis. The deformity in the stomachs varied from an irregularity along the curvatures to hour-glass contracture, and in one case to extreme distortion, giving the appearance not unlike that of a dumb-bell. Response to treatment has been astonishing in each case, and bears witness to the value of the therapeutic test.

The pathologic diagnosis of syphilis of the stomach is even more difficult to establish with certainty than the clinical diagnosis, as syphilitic infiltration so without much doubt if the history and clinical findings are given proper consideration. In the congenital cases, the family history and the early history of the patient, his general development and appearance and other syphilitic stigmata with symptoms of gastric disturbance are very suggestive, while in the acquired cases a definite history of infection may be established. In both instances, the course of the disease differs from the simple type of ulcer, in that it is influenced but little by dieting and the ordinary meth-

3. Lockwood, G. R.: Diseases of the Stomach, Philadelphia, Lea and Febiger, 1913, p. 305. closely resembles tuberculosis. In two of our series, Cases 4 and 5, specimens wcre removed for microscopic examination. In Case 4 a nodule the size of an almond was removed from the surface of the liver, which was studded with such tumors varying in size from a pea to a walnut. Macroscopically, this was a typical syphilitic liver. Dr. Wood, pathologist to St. Luke's Hospital, did not feel justified in making a positive report of syphilis from the morphology.

A fair sized piece of gastric mucosa and an omental gland 1.5 by $0.6 \mathrm{~cm}$. were removed from Case 5 for examination, and the report on the sections from the 
mucosa states that the diagnosis must remain in doubt with the probability that the condition is syphilis rather than tuberculosis. Sections of the gland showed simple inflammatory reaction. (For detailed pathologic report of these two cases, see histories.)

Roentgen-ray findings in syphilis of the stomach may be divided into three classes: first, a fairly typical change consisting of a diminished size and dumbbell-like appearance of the stomach due to deformity caused by infiltration involving the middle or pyloric half of the stomach, this portion representing the handle of the dumb-bell. In this type the pyloric sphincter may be involved and held open so that the stomach empties, or at least begins to empty in a very rapid manner, such as has been observed in carcinomatous infiltration of the pylorus where the pylorus is held open, or in spontaneous or artificial gastro-enterostomy. But even though the stomach begins to empty in a very rapid manner, there may be a trace of food remaining high up at the cardiac end at the sixth hour.

Secondly, the findings may be similar to those in the first type except that the involvement of the pylorus or the extreme stenosis of the infiltrated portion of the body of the stomach may cause delay in the emptying of the stomach such as occurs in ulcer or carcinoma.

In both the first and second types, however, the stomach appears to be smaller than normal, and there is apt to be a tendency to compensatory dilatation of the esophagus to

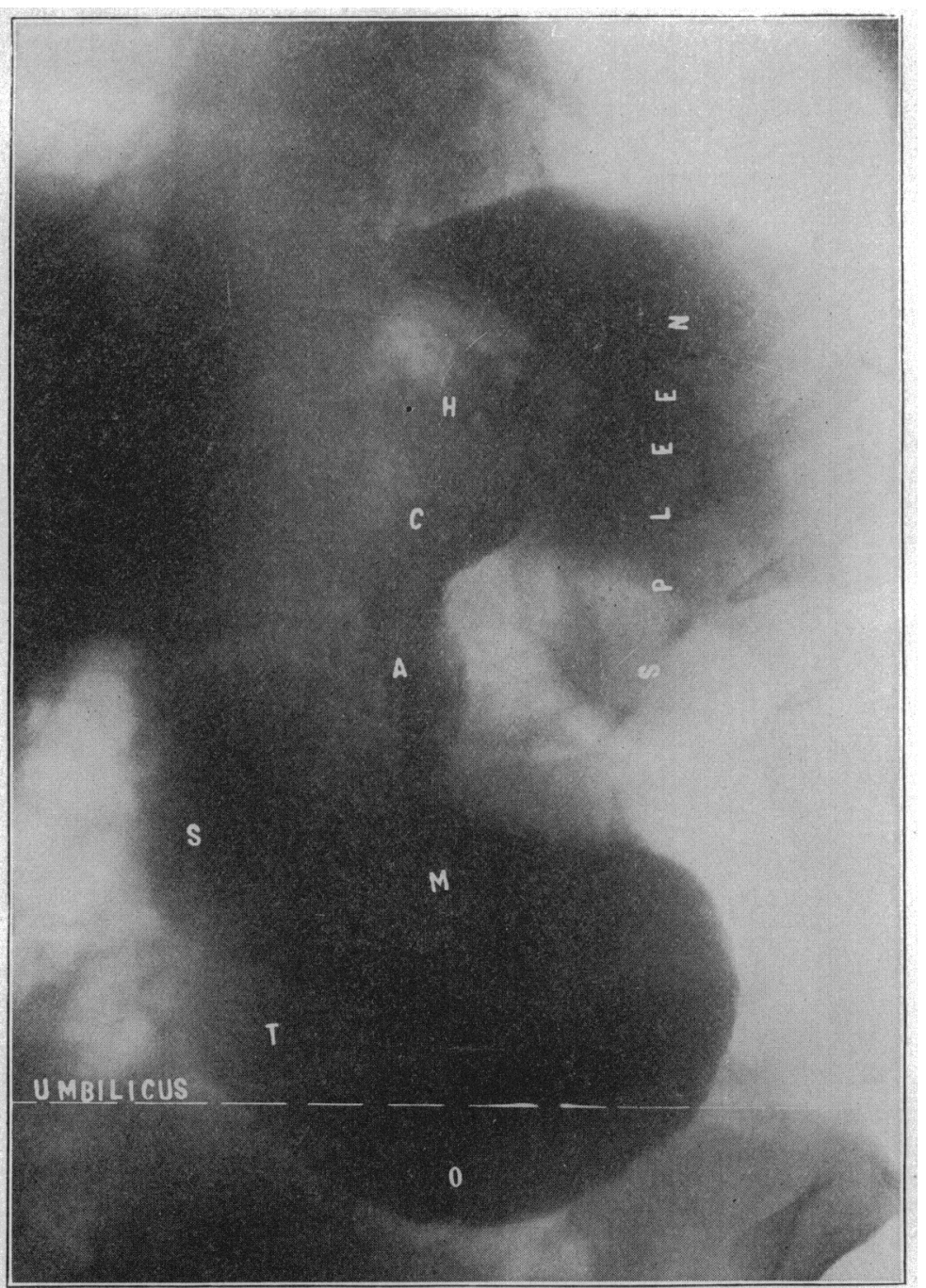

Fig. 2 (Case 4).-Woman, aged 34. Note hour-glass constriction with long charnel between pouches. Condition confirmed at operation and relieved by brcaking up of perigastric adhesions and performance of gastro-enterostomy to the lower pouch. the rapid response to proper treatment in nearly all reported cases, that stenosis of any extent or duration could be easily prevented. However, when ulceration and cicatrization have taken place, surgical measures play an extremely important rôle in the treatment of this condition, and should not be too long postponed. Three cases, 6, 7 and 8, showed little or no obstruction by Roentgen examination, and for this reason the question of operation was deferred until after vigorous antiluetic treatment had been given a trial. There was immediate response in each case, and now, from six to eighteen months later, all three patients are in good health. It will be noted from the histories of these patients that pain was the most prominent symptom, and not vomiting, as was the rule in the obstructed cases. Persistent vomiting with increasing $10 \mathrm{~s}$ s of flesh and strength is by far the most frequent complication requiring operative relief. Gastroenterostomy best meets the indication, and was the operation employed in five of the cases here reported. In three instances, involvement of the stomach wall was so extensive that it was difficult to find a fit place to make the anastomosis. Jejunostomy should be borne in mind, and would be preferable to a difficult gastroenterostomy in a bad risk. Pylorectomy and the excision of ulcers are usually contraindicated on account of coexisting 1 es io n s. The former operation could have been performed in Case 2, but the presence of tabes seemed to be sufficient contraindication. In make up for the diminished capacity of the stomach.

In the third type the infiltration may involve only the pyloric region, in which case the findings may resemble closely those found in cicatrized ulcer in this region and may be accompanied by dilatation of the stomach.

The treatment of gastric syphilis is, strictly speaking, medical; and if the diagnosis could be made while the disease is in the stage of infiltration, there should be no complications requiring operative intervention. Even though the pylorus is encroached on in the early stage, there is reason to believe, from
Case 3, also of the pyloric stenosis type, there was marked fixation to the liver and the man was in poor condition; but we so placed the anastomosis that a two stage operation could be undertaken. Improvement was so rapid and satisfactory that the patient refused a second operation. We are aware of the fact that all gastric ulcers, syphilitic or otherwise, have potential dangers, and for this reason the question of resection should be considered in every suitable case. If there is sufficient evidence, however, to make a diagnosis of syphilis of the stomach, no case should be subjected to more than the simplest form of operation 
necessary to relieve urgent symptoms until after antiluetic treatment has been given a reasonable trial.

\section{SUM MARY}

Syphilis of the stomach occurs much more frequently than was formerly supposed. The Wassermann reaction and roentgenologic examinations have provided the missing data necessary to establish the diagnosis. These aids to diagnosis should be applied in every case of disease of the stomach. If the diagnosis is made reasonably early, antiluetic treatment should control the symptoms; if not made until late in the disease, surgical intervention may become necessary to relieve complications.

\section{REPORTS OF CASES}

Case 1.-History.-H. D., girl, aged 14, admitted to St. Luke's Hospital, June 10, 1913, whose father was living and whose mother had died of apoplexy, had never been strong; she had had more or less pain in stomach after eating as long as she could remember. For two years the eating of solid food had caused vomiting and severe pain; she lived on fluid diet six months and now swallowing of liquids caused pain and was frequently accompanied by vomiting; she never vomited blood. Examination revealed emaciated body with sallow skin; eyes negative; bad teeth; palpable glands in postcervical chains; lungs normal; heart showed a systolic murmur. Abdomen retracted, not tender on palpation, liver palpable $3 \mathrm{~cm}$. below the costal margin; spleen enlarged. Extremities normal. Weight 52 pounds. Test mea 1 showed free hydrochloric acid 0 , total acidity 32 , blood positive. Wassermann reaction four plus positive. Hemoglobin 50 per cent.

Roentgen Examination. - The food passed into the cardiac end of the stomach, which it soon filled, and then backed up into the esophagus; only a trace passed through a very long, narrow, stenosed portion of the stomach extending from the cardiac end to the pyloric region, where a slight pouch was then evident. This gave a peculiar dumb-bell-like appearance to the stomach outline-one portion of the dumb-bell being formed by the cardiac end and the other portion by the pyloric end with a long narrow handle part of the dumb-bell between. The patient was then studied carefully in various positions, and the deformity of the stomach found to be constant. The stomach failed to empty itself within six hours. The following day a confirmatory examination was undertaken, and showed that the peculiar deformity of the stomach persisted. The patient was then admitted to the hospital and a third examination was made of the stomach, which confirmed the finding of stenosis of the body of the stomach producing dumb-bell-shaped deformity. Syphilis of the stomach was suggested as a possible diagnosis from the Roentgen examination.

Operative Indication: Persistent vomiting due to deformed stomach.

Operation.-July 12, 1913, a posterior gastro-enterostomy to the cardiac pouch was done with considerable difficulty owing to adhesions and size of pouch. Recovery was uneventful; no vomiting occurred until the tenth day. This was due to taking food in too large quantities and was relieved by properly regulating feedings.

Pathologic Findings.-The middle half of the stomach is occupied by an infiltrated mass which has practically destroyed the lumen. The greater curvature is drawn up to the lesser. There is a small pyloric pouch which connects with a moderate-sized cardiac pouch by a long narrow channel into which a finger cannot be invaginated. At some points the wall is infiltrated and has a cloughy feel, while other portions are hard and fibrous. The wall of both the cardiac and pyloric pouches is thickened. There are many perigastric adhesions. The liver is enlarged and grayish.

Two weeks after operation the patient was referred for Roentgen examiriation on account of vomiting. This examination showed that the gastro-enterostomy was working satisfactorily, but that the child was overtaxing the capacity of the stomach by taking too much food as she began to improve in health and appetite. It was plain to see from the Roentgen ray that food backed up into the esophazus owing to its being taken in greater quantities than the gastroenterostomy could take care of (Fig. 1). Based on this examination, feeding in smaller quantities but at more frequent intervals was advised. Vomiting ceased and gain in weight followed. The patient was examined at intervals of several months up to the present time. The deformity of the stom ach persisted, but the gastro-enterostomy worked perfectly, taking most of the food from the stomach; but graciually more of the food appeared to be going through the pylorus, suggesting that possibly some of the stenosis was being relieved by the antisyphilitic treatment. The constipation, which was a marked feature in the case before the operation, has been entirely relieved, and this is borne out by the passage of the bismuth meal through the colon in normal time. The last examination, made Feb. 11, 1915, one year eight months after gastro-enterostomy, showed that there was now very little tendency to backing up into the esophagus.

The patient was discharged July 17, 1913. On being examined Feb. 11, 1915, the patient was found to have gained 20 pounds in weight, was eating solid food, and was improved in every way.

CASE 4.-History.-G. R., widow, aged 34, admitted to St. Luke's Hospital, Jan. 4, 1915, had a negative previous history, two children and no miscarriages. Ten years ago she had a severe attack of epigastric pain with vomiting of blood; one 
year later she noted a swelling in the abdomen just to the right of the umbilicus. She had had attacks of pain in the upper abdomen from time to time which had no relation to the taking of food, usually radiating to the back and frequently requiring morphin; she had had attacks of vomiting at irregular intervals; the vomitus usually consisted of food recently taken and did not contain blood. One attack of jaundice occurred about five years ago. The swelling on the right side had increased in size until now she could feel a mass the size of an orange, not tender, and there was only occasional pain in this region. Her general appearance was that of a poorly nourished woman appearing many years older than the age given; color bad; eyes negative; heart and lungs normal. Liver edge palpable $1 \mathrm{~cm}$. below the costal margin. In the right upper quadrant was a rounded tumor mass the size of an orange which moved with respiration, seemed to be attached to the liver, and was slightly tender. Reflexes normal. Weight 116 pounds. Wassermann reaction four plus positive. Tuberculin reaction negative. Fasting stomach showed 65 c.c. of greenish fluid containing mucus and strands, small particles of food and blood clots. Bile plus, lactic acid 0 , free hydrochloric acid 13 , total acidity 34.

Roentgen Examination.-This revealed the stomach as having the appearance of being deformed, of an hour-glass-like appearance. The lower pouch of the stomach appeared to be dilated and reached to a point 1 inch below the umbilicus, the upper half very much narrowed (Fig. 2). (There is a distinct shadow indicating an enlarged spleen.) The pyloric region appeared to be somewhat deformed, suggesting a spasmodic condition or pressure. At the sixth hour there was a large residue in the stomach, the shadow of which measured 4 by 3 inches. At the twenty-fourth hour there was still some bismuth remaining in the stomach.

Operative Indications: Hourglass stomach with retention; abdominal tumor probably distended gallbladder.

Operation.-Jan. 13, 1915, a posterior gastro-enterostomy to distal pouch, cholecystectomy and division of perigastric allhesions was performed, with excision of the nodule from liver. As the cardiac pouch was small and difficult to expose, and the channel connecting the pouches sufficiently wide to admit three fingers, it seemed best to unite the intestine to the distal pouch.

Pathologic Findings.-The stomach was exposed with considerable difficulty, as it was adherent to the parietal peritoneum and the under surface of the left lobe of the liver. The anterior wall and greater curvature of the stomach showed an extensive cicatrix resulting from an ulcer which gave the appearance of having healed at one part and still being active at another.

The perigastric adhesions, together with the ulcer, had formed an hour-glass constriction, which was situated at the junction of the upper and middle thirds of the stomach. Division of the adhesions resulted in liberating the stomach to the extent that a channel was formed between the pouches which would admit three fingers. The pyloric end of the stomach was bound to the under surface of the right lobe of the liver by adhesions and would barely admit one finger. The gallbladder was distended to the size of a large pear; the cystic duct was occluded by a single stone; the liver was enlarged, the capsule thickened, containing many nodules varying in size from that of a pea to an English walnut.
Convalescence was straightforward. March 19, 1915, the patient had gained 20 pounds and felt well. Roentgen examination showed the gastro-enterostomy working satisfactorily, but the deformity of the stomach persisted.

Pathologic Report.-Sections from liver show marked degeneration and areas of necrosis of the parenchyma. There is marked general infiltration with round cells and many structures showing tuberclelike masses which contain giant cells of the Langhans type. There is moderate connective tissue proliferation, and occasional areas showing granulation tissue of the tuberculous type, with many endothelial cells and areas of caseation. Multinucleated giant cells are not found except in the tubercles. No tubercle bacilli are found in sections stained with carbolfuchsin, and no Spirochaetae pallidae in Levaditi preparations. The liver substance is almost entirely replaced by the growth, and the diagnosis must be left in doubt with the probability that the condition is syphilis rather than tuberculosis.

CASE 5.-History.-F. G., woman, aged 23, admitted to St. Luke's Hospital, Jan. 15, 1915, had been married three years, and had one child, and no miscarriages. For the past eight months she had had an aching pain and sense of epigastric distress coming on immediately or within half an hour after eating, accompanied by nausea and sometimes vomiting, which relieved the pain. This pain radiated into the neck and toward the umbilicus. For the past two months she had vomited constantly; there was no blood in the vomitus or stools; the patient was hungry, but could not retain food. She had lost 22 pounds in the past eight months. Her general appearance was that of a poorly developed, emaciated woman. Palpable cervical lymph nodes; systolic murmur at the apex; right lung dull at apex. Breath sounds harsh and high-pitched, expiration prolonged. A few sibilant râles at base. Abdomen scaphoid and tender at costovertebral angles. Palpation showed a firm indefinite mass in the epigastrium above and to the left of the umbilicus. Knee jerks absent. Weight, 88 pounds. Wassermann reaction four plus positive. Tuberculin reaction negative. No report on gastric contents. Wassermann on husband showed four plus positive.

Roentgen Examination.-This revealed a peculiar break in the bismuth shadow at the pyloric end of the stomach; further examination showed the peculiar filling defect in the pyloric end of the stomach to be permanent, indicating some infiltration of the stomach wall very much as occurs in a new growth (Fig. 3). At the sixth hour there was a distinct residue in the stomach, the shadow of which measured $11 / 2$ inches in diameter. The filling defect still persisted in the pyloric end of the stomach, especially along the greater curvature. At the twenty-fourth hour there was a trace of bismuth still remaining in the stomach.

Operative Indications: Pyloric obstruction with persistent vomiting.

Operation.-Jan. 27, 1915, a posterior gastro-enterostomy was performed, with excision of gland and portion of stomach wall for examination.

Pathologic Findings.-Extending from the middle of the greater curvature to the pylorus was an irregular mass involving the entire thickness of the stomach wall in such a way as to pucker the pyloric portion of the stomach, thereby causing stenosis of the pylorus. This mass was doughy in feel and the 
peritoneum covering it was edematous. There were numerous glands in the gastrocolic omentum, the greater omentum and about the greater curvature. No special changes were noted in the appearance of the liver.

Convalescence was straightforward with mixed treatment and neosalvarsan. The patient was discharged Feb. 25, 1915. Roentgen examination one month after operation showed that the gastro-enterostomy was working, but the deformity at the pyloric region of the stomach still persisted.

Pathologic Report.-Microscopic Examination: The gastric mucosa shows congestion, edema and dense cellular infiltration of the glandular structures. The glands themselves are much atrophied, especially in the deeper layers, where they are completely involved in the infiltration. Remnants of atrophic glands are found in the submucosa. Very little of the muscular coat is included in the material received at the laboratory. In the submucosa there is a very dense infiltration entirely replacing the normal structures, composed of flat endothelioid lymphocytes and diffuse tuberclelike masses. These tubercles contain large giant cells of the Langhans type. The tubercles are not quite so well defined as those seen in tuberculosis, and yet the structure is rather more rich in cells and giant cells than the ordinary gumma. The vascular lesions are not wholly characteristic of syphilis, but there is a certain amount of subendothelial proliferation, and in some places the vessels are obliterated by a growth of new endothelial cells. There is but little perivascular infiltration, especially in those areas outside of the specific lesion. Practically no necrosis is present in the lesion. Sections stained by the Levaditi method failed to show the Spirochaeta pallida, and no tubercle bacilli could be demonstrated. Sections from the lymph node show slight inflammatory reaction with moderate endothelial hyperplasia and distention of the lymph sinuses. The lesions in the mucosa and submucosa of the stomach are not characteristic of either syphilis or tuberculosis, but the absence of much necrosis and the diffuse nature of the infiltration, together with the vascular changes, point rather toward syphilis than toward tuberculosis. An absolute diagnosis, however, is not possible from the specimen received.

CASE 6.-History.-W. H., boy, aged 17, admitted to St. Luke's Hospital, Oct. 30, 1913, whose mother died of typhoid and father of arteriosclerosis, had been informed that he had inherited a certain disease from his father. For five years he had had discomfort in the region of the stomach. Eight months ago the pain became acute, but was intermittent in character, coming on two or three times a day without relation to eating. The patient had vomited at irregular intervals, but not persistently. He had no appetite, living principally on fluids. $\mathrm{He}$ was given four injections of salvarsan at the Rockefeller Institute beginning five weeks ago, followed by much improvement. He was able to eat more, but still suffered pain, which was attributed to a possible appendicitis. His general appearance was that of a poorly nourished boy, aged 17 , but looking to be about 12 . Pupils reacted sluggishly to light; teeth poor and slightly notched; cervical lymph nodes enlarged. Heart and lungs normal. Abdomen soft, normal to palpation. Knee jerks present. Weight 68 pounds. Height 5 feet $1 / 2$ inch. Red blood cells 4,500,000. Hemoglobin 50 per cent.

Roentgen Examination.-This showed the stomach imperfectly filled out along the greater curvature (Fig. 4). The stomach was moderately dilated. There was a distinct residue at the sixth hour, and deformity of the pyloric third of the stomach which, with the previous findings and the history of positive Wassermann reaction, was sufficient to warrant a diagnosis of syphilis of the stomach. The patient continued on antisyphilitic treatment. $\mathrm{He}$ was discharged from the hospital, Nov. 7, 1913, and was referred back to the Rockefeller Institute, where he has been under continuous observation and treatment with the result that there has been a remarkable change in his condition.

Roentgen examination, March 2, 1914, showed that the deformity at the pyloric end of the stomach persisted. At the sixth hour there was a distinct residue in the stomach. March 18, 1914, the patient was again examined fluoroscopically and roentgenographically. This confirmed the findings of a deformity at the pyloric end of the stomach. There was less residue at the sixth hour than in the previous examination. March 14, 1915, Roentgen examination showed the pyloric end of the stomach still deformed, but at the sixth hour the stomach had emptied itself. At this time the weight had increased to 97 pounds; pain had disappeared and the patient was now able to eat and digest all sorts of food.

\section{THE OPEN TREATMENT OF INFECTED WOUNDS}

\section{A PRELIMINARY REPORT}

\section{FREDERICK G. DYAS, M.D. CHICAGO}

The development of the surgical treatment of infected wounds has witnessed the use of a vast variety of substances and methods in the attempt to assist the healing powers of the individual. In the present aseptic era of surgery the treatment of an infected wound means in most cases the establishment of adequate drainage by various means and the application of voluminous dressings, either dry, sterile or moist antiseptic.

Pathology teaches us, and it is within the experience of every medical man, that the destruction of tissue caused by moist gangrene is far greater than that caused by dry gangrene. With this fundamental truth in mind I have endeavored to convert wounds, which in every way corresponded to moist gangrene, into areas of dry gangrene. Everyone is familiar with the crude methods employed by the Indians and other savage tribes for the preservation of carcasses of animals killed. These carcasses are placed high above the ground on the limbs of trees in order that the blood may drain from the muscles and that the tissue juices might be evaporated by the winds and sun. By this method meat may be preserved free from mold and putrefaction for a very long time.

It is a fundamental principle of bacteriology that heat and moisture are necessary for the growth and propagation of practically all pathogenic bacteria. Therefore, if it were possible to dry up the tissues and dehydrate the infected area, the invading organisms must be, if not entirely killed, at least greatly attenuated.

When an animal suffers a wound, usually in one of the extremities, it is a matter of common observation that the pus is licked from the suppurating area if it be within reach of the animal's tongue. No bandage is put around the affected area, which is exposed to the air and, in many cases, to the sunlight. As the result of this, one rarely sees the intensely infected wounds in the lower animals which one observes daily in a human being in the wards of a large general hospital. This is in harmony with the recent observations among the wounded on the battlefields of Europe. Infected wounds heal more rapidly under the influence of autogenous vaccines or serums, whether prepared scientifically or obtained by sucking the wound or chewing pus soaked bandages.

Furthermore, the treatment of all degrees of burns by the open air method is practically the uniform procedure in the hands of every experienced surgeon. By this method there is a rapid desiccation of the sloughing tissues and a drying up of the foul discharges. The absorption of toxic materials into the general cir- 